\title{
Kernos
}

Revue internationale et pluridisciplinaire de religion grecque antique

$25 \mid 2012$

Varia

\section{Nicole BELAYCHE, Jean-Daniel DUBOIS (dir.), L'oiseau et le poisson. Cohabitations religieuses dans les mondes grec et romain}

Vinciane Pirenne-Delforge

\section{(2) OpenEdition}

\section{Journals}

Édition électronique

URL : http://journals.openedition.org/kernos/2092

DOI : 10.4000/kernos.2092

ISSN : 2034-7871

Éditeur

Centre international d'étude de la religion grecque antique

Édition imprimée

Date de publication : 26 octobre 2012

Pagination : 382-383

ISSN : 0776-3824

Référence électronique

Vinciane Pirenne-Delforge, « Nicole belayche, Jean-Daniel dubois (dir.), L'oiseau et le poisson.

Cohabitations religieuses dans les mondes grec et romain », Kernos [En ligne], 25 | 2012, mis en ligne le 01 octobre 2012, consulté le 21 septembre 2020. URL : http://journals.openedition.org/kernos/2092 ; DOI : https://doi.org/10.4000/kernos.2092

Ce document a été généré automatiquement le 21 septembre 2020.

Kernos 


\title{
Nicole BELAYCHE, Jean-Daniel DUBOIS (dir.), L'oiseau et le poisson. Cohabitations religieuses dans les mondes grec et romain
}

\author{
Vinciane Pirenne-Delforge
}

\section{RÉFÉRENCE}

Nicole BELAYCHE \& Jean-Daniel DUBOIS (dir.), L'oiseau et le poisson. Cohabitations religieuses dans les mondes grec et romain, Paris, Presses de l'Université Paris-Sorbonne, 2011. 1 vol. $16 \times 24 \mathrm{~cm}, 410$ p. (Religions dans l'Histoire). ISBN : 978-2-84050-800-7.

1 Le titre est poétique et renvoie à une interrogation imagée : L'oiseau et le poisson peuvent tomber amoureux, mais où iront-ils construire leur nid ? C'est évidemment la question de la cohabitation, dégagée par le sous-titre, qui se cache derrière la métaphore, et plus précisément encore les cohabitations religieuses de l'antiquité gréco-romaine. Le programme de recherche à l'origine de cette publication était ambitieux et l'introduction du volume collectif en précise les contours. Il ne s'agit pas de rouvrir le dossier général des influences et autres interactions culturelles connues sous les étiquettes lâches d' «hellénisation" ou de «romanisation». De façon plus pragmatique, les chercheurs ont travaillé sur des dossiers qui s'inscrivent dans trois axes principaux : les terrains de rencontre, les espaces, les langages, qui forment autant de parties du livre (1. Quand païens, juifs et chrétiens cohabitent ${ }^{1} ; 2$. Territoires occupés ou partagés par plusieurs groupes religieux ${ }^{2} ; 3$. Être soi en parlant le langage de l'autre ${ }^{3}$ ) auxquelles s'ajoute une dernière qui regroupe des contributions illustrant la combinaison de méthodes dès qu'il s'agit de travailler en comparatiste (4. Historiens et anthropologues face aux cohabitations religieuses ${ }^{4}$ ). Mais certaines des contributions de cette $4^{\mathrm{e}}$ partie auraient pu tout aussi bien trouver place dans l'une des trois 
premières. Quoi qu'il en soit de ce point de détail de l'organisation du livre, il fourmille d'un matériau utile pour tout historien des religions antiques, tant par les dossiers précis qu'il propose que par les questions de méthode que sa lecture soulève tout au long. En un temps où le "vivre ensemble» est une problématique d'actualité lancinante, une meilleure connaissance des situations connues et des solutions adoptées par des communautés humaines du passé peut ouvrir des perspectives qui dépassent l'érudition et l'histoire, même s'il s'agit néanmoins de cela avant tout.

2 L'historien de la religion grecque trouvera incontestablement du grain à moudre dans toute une série d'articles, là où l'on évoque sacrifices sanglants et non sanglants (A. Van de Kerchove), les catabases mythologiques (R. Gounelle), les approriations de genres littéraires ou de types iconographiques traditionnels (G. Agosti, A.-Fr. Jaccottet), ainsi que les diverses facettes du processus d'interpretatio à l'œuvre à Rome, en Égypte, en Phénicie (Fr. Prescendi, G. Tallet, Fr. Duyrat). La question des espaces, urbains ou autres, tant dans leur organisation que leurs appropriations successives, est aussi fort éclairante et méthodologiquement la plus élaborée dans le volume (J. Scheid, Fr. de Polignac, A.-V. Pont, Fr. Van Haeperen, N. Belayche \& A.-R. Hošek). En somme, une excursion comparatiste qui vaut la peine. Quant à la réponse à la devinette liminaire, elle n'est simple qu'en apparence : l'oiseau peut faire un nid sur l'eau...

\section{NOTES}

1. D. STÖCKL BEN EZRA, Interaction et différenciation. Quelques pensées sur les rôles des fêtes juives, chrétiennes (et "païennes»). A. CAMPLANI, Perception de l'altérité religieuse et identité culturelle : l'élite d'Édesse entre les III et $V^{e}$ siècles. A. VAN DEN KERCHOVE, Les hermétistes et les conceptions traditionnelles des sacrifices. J. SCHEID, Les chrétiens et le bois sacré de Dea Dia.

2. Fr. DE POLIGNAC, Un système religieux à double visage dans un espace intermédiaire: l'exemple de l'Amphiaraion d'Oropos. Fr. VAN HAEPEREN, Cohabitations religieuses à Ostie, port de Rome. A.-V. PONT, La place du culte impérial dans l'espace urbain d'Éphèse: initiative, contrôle, interprétation. G. FILORAMO, Cohabitations et contacts religieux dans le monachisme de Gaza à travers la correspondance de Barsanuphe et de Jean de Gaza. R. GOUNELLE, Entre Bible et mythologie gréco-romaine : la descente du Christ aux enfers dans les Sermons XII et XIIA d'Eusèbe dit de Gaule.

3. Fr. PRESCENDI, La déesse grecque Ino-Leucothée est devenue la déesse romaine Mater Matuta : réflexions sur les échanges entre cultures "voisines». A.-Fr. JAcCOTTET, Du baptême de Dionysos à l'initiation du Christ: langage iconographique et identité religieuse. G. TALLET, Zeus Hélios Megas Sarapis, un dieu égyptien "pour les Romains»? J.-D. DUBoIs, Jésus assis au Temple ou sur le Temple. Remarques sur le préambule de l'Apocalypse copte de Pierre (NHC VII, 3). G. AGOSTI, Usurper, imiter, communiquer: le dialogue interculturel dans la poésie grecque chrétienne de l'Antiquité tardive.

4. Ph. MATTHEY, Récits grecs et égyptiens à propos de Nectanébo II : une réflexion sur l'historiographie égyptienne. Fr. DUYRAT, Interpretatio Graeca et identité sémitique. Les divinités sur les monnaies de Phénicie hellénistique. A. DESTRO, M. PESCE, Le voyage céleste, tradition d'un genre ou schéma culturel en contexte? N. BELAYCHE, A.-R. HoŠEK, Anatomie d'une rencontre dans des constructions volontaires: les colonies de l'Orient romain. 


\section{AUTEURS}

VINCIANE PIRENNE-DELFORGE

F.R.S.-FNRS - Université de Liège 